\title{
Polyamide Amino Acids trimers as TAR RNA ligands and anti-HIV agents
}

\author{
Vanessa Bonnard $^{\mathrm{a}}$, Lise Pascale ${ }^{\mathrm{a}}$, Stéphane Azoulay ${ }^{\mathrm{a}}$, Audrey Di Giorgio ${ }^{\mathrm{a}}$, Christine Rogez-Kreuz ${ }^{\mathrm{b}}$, \\ Karine Storck $^{\mathrm{b}}$, Pascal Clayette ${ }^{\mathrm{b}}$, Nadia Patino ${ }^{\mathrm{a}, *}$

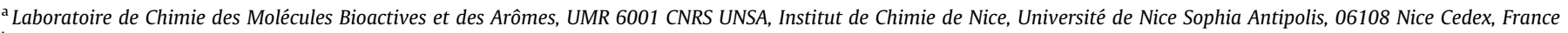 \\ ${ }^{\mathrm{b}}$ Neurovirology Department, SPI-Bio, CEA, 18 route du Panorama, BP 6, 92265 Fontenay-aux-Roses Cedex, France
}

\section{A R T I C L E I N F O}

\section{Article history:}

Received 3 June 2010

Revised 30 August 2010

Accepted 1 September 2010

Available online 7 September 2010

\section{Keywords:}

Polyamide Amino Acids

TAR RNA ligands

Anti-HIV agents

\begin{abstract}
A B S T R A C T
Based on a split-and-mix strategy, a library of trimeric Polyamide Amino Acids (PAA) incorporating four different amino acids (Lys, Ala, Arg, and Phe) has been prepared. Screening of the batches for HIV TAR RNA binding in a fluorescent assay allowed the identification of several components that interact with TAR RNA at a micromolar concentration, with a good TAR versus tRNA specificity. Some of these compounds compete efficiently with the association of TAR and Tat protein. In cell cultures, these compounds display a moderate antiviral activity, associated nevertheless with some toxicity. Overall, these results confirm that this new family can be a basis for the design of novel RNA targeting drugs.
\end{abstract}

(C) 2010 Elsevier Ltd. All rights reserved.

\section{Introduction}

Small molecules that recognize and bind a three-dimensional RNA structure with high affinity and specificity may provide new types of drugs that exert their effects by inhibiting the biological function of the RNA target. ${ }^{1,2}$ In this context, considerable efforts have been directed to the finding of specific ligands of the HIV-1 TAR RNA fragment, a 59-base stem-loop structure located at the 5 -ends of all nascent HIV-1 transcripts. ${ }^{3,4}$ A key step during the HIV-1 transcription is the recognition of TAR RNA by the viral regulatory Tat protein, which assembles along with host cell factors (CDK9 and cyclin T1) to form a ternary complex, resulting in a drastic increase in the number of viral transcripts. ${ }^{5-8}$ Because the formation of this complex is essential for HIV replication, the development of inhibitors of this interaction could provide the basis for new antiviral therapies. Several low molecular-weight compounds have been reported that block in vitro the Tat/TAR interaction, among which intercalators, aminoglycoside derivatives, peptides, and peptidomimetics. ${ }^{9}$ Although some of them show viral inhibition in cellular assays, none has yet advanced to the clinic. Therefore, it is of continued interest to search for new low molecular-weight molecules that bind with high affinity and selectivity to TAR and inhibit the formation of the ternary complex and, consequently, HIV replication.

\footnotetext{
Abbreviations: NMP, $N$-methyl-2-pyrrolidinone; DIPEA, N,N-diisopropylethylamine; HBTU, 2-(1-H-benzotriazol-1-yl)1,1,3,3-tetramethyluroniumhexafluorophosphate; Pyr, pyridine; TFA, trifluoroacetic acid; TFMSA, trifluoromethanesulfonic acid; $\mathrm{Ac}_{2} \mathrm{O}$, acetic anhydride; TIS, triisopropylsilane; $\mathrm{DCM}$, dichloromethane.

* Corresponding author. Tel.: +3304920761 46; fax: +330492076151.

E-mail addresses: pascal.clayette@cea.fr (P. Clayette), patino@unice.fr (N. Patino).
}

As part of our efforts to identify new types of specific RNA ligands, we have recently designed a new family of compounds, named 'Polyamide Amino Acids (PAA)', which are constituted by repetitive 2aminoethyl glycyl units (e.g., the Polyamide Nucleic Acids backbone; PNA: oligonucleotide analogs), onto which $\alpha$-amino acid residues are grafted (Fig. 1A). Preliminary studies on eight tetra-PAA models, based on four selected amino acids (Alanine (A), Phenylalanine (F), Arginine (R), and Lysine (K); Fig. 1B), highlighted the potential of these new compounds to behave as TAR RNA ligands, which bind their target via both electrostatic and non-electrostatic interactions, the affinity and tRNA versus TAR specificity depending on the nature of the amino acid residues. ${ }^{10}$ Very interestingly, these tetra-PAA displayed also a high TAR RNA versus DNA selectivity.

In parallel to this work, and with the aim of establishing 'structure-activity' relationships, a library of PAA trimers, including the four amino acids $\mathrm{A}, \mathrm{F}, \mathrm{R}$, and $\mathrm{K}$, was also prepared and the binding to the TAR RNA fragment (Fig. 1C) was investigated. In this paper, we report the 'split and mix' synthesis of this library and of selected individual tri-PAA, as well as their TAR RNA binding affinity and specificity. The ability to inhibit the TAR/tat complex and the anti-HIV activity and cytotoxicity in PBMCs were also assessed.

\section{Results and discussion}

\subsection{Synthesis}

\subsubsection{Library synthesis}

The tri-PAA library was prepared following an on-resin split-andmix strategy, starting from Boc-protected PAA (Ala) and (Phe), and Boc-/Z-protected PAA (Lys) and (Arg) monomers (Fig. 2A). Following 


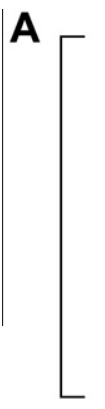

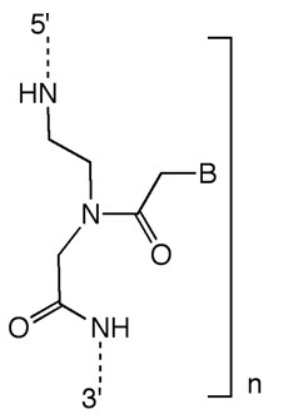

PNA

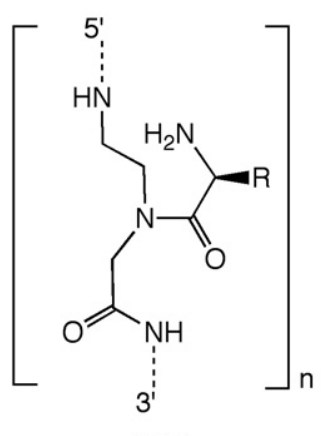

B<smiles>[X]C(=O)CN(CCNC)C(=O)[C@@H](C)N</smiles>

R: $\mathrm{CH}_{3} ; \mathrm{CH}_{2}-\mathrm{Ph} ;\left(\mathrm{CH}_{2}\right)_{4}-\mathrm{NH}_{2} ;\left(\mathrm{CH}_{2}\right)_{3}-\mathrm{NH}-\mathrm{C}\left(\mathrm{NH}_{2}\right)=\mathrm{NH}$

$X=\beta$-alaninamide

$$
\text { C } \begin{array}{r}
5^{\prime} \mathrm{C}_{18} \mathrm{CAGA} \cup \mathrm{C}_{\mathrm{GAGC}}{ }^{\mathrm{C}} \mathrm{U}_{\mathrm{G}} \\
3^{\prime} \mathrm{G}_{44} \mathrm{GUCU} \longrightarrow \mathrm{CUCG}{ }_{A \mathrm{G}}^{\mathrm{G}}
\end{array}
$$

Figure 1. (A) Polyamide Nucleic Acids (PNA) versus Polyamide Amino Acids (PAA) structures. (B) Series of tetra-PAA previously studied. ${ }^{10}$ (C) Secondary structure of the TAR RNA fragment used in this study.

this combinatorial strategy, the 64 compounds constituting the library were divided into four sub-libraries of 16 tri-PAA, with respect to the nature of the PAA located at the C-extremity $\left(\mathrm{SL}\left(\mathrm{AA}_{1-4}\right)\right)$. Each of these sub-libraries was further split into four batches of four tri-PAA. Each batch is characterized by the nature of the two PAA monomers located at the $\mathrm{N}$ - and C-extremities (Fig. 2B).

The synthesis of each sub-library was performed as illustrated in Figure 2C: $\beta$-alanine functionalized MBHA-LL resin was coupled to one of the four N-protected PAA monomer, using an HBTU procedure. Unreacted amino groups on the resin were capped with a $\mathrm{Ac}_{2} \mathrm{O} /$ pyridin/NMP solution. The resin was then split into four portions and each portion was reacted with a TFA/TIS (9:1) solution for Boc cleavage. Then, a second PAA selected among the four Nprotected PAA monomers was introduced following the same elongation procedure. After capping, the four portions were mixed then split again into four batches. Each batch was subjected to a Boc deprotection then to the elongation procedure with the third PAA among the four N-protected PAA monomers. After Boc cleavage and N-acetylation of the terminal PAA residue, each batch was submitted to acidolysis (TFMSA/TFA/TIS (1:8:1) solution) for the cleavage of the tri-PAA from the support and the concomittant Zdeprotection for the Arg- and/or Lys-containing batches. Precipitation from cold diethyl ether and subsequent lyophylisation from water gave the sub-library as four batches of four tri-PAA each in good yields. These mixtures were desalted by HPLC semi-preparative and their composition was verified by ESI MS experiments.

\subsubsection{Individual tri-PAA synthesis}

Global interaction studies of the 16 batches led us to synthesize individually 28 tri-PAA (1-28). Their synthesis was performed as described above for the preparation of the sub-libraries (Fig. 2C). It should be noted that tri-PAA incorporating two and three Arg residues were obtained in lower yields than the other ones (HPLC yields from $58 \%$ to $85 \%$ ). Mono, di, and tri acetylated derivatives were identified as by-products by MS experiments, likely demonstrating that under the acid conditions of Boc cleavage, partial Zdeprotection of guanidinium moieties occurred, leading to their acetylation during capping steps. All the 28 tri-PAA were easily purified by semi-preparative reverse-phase HPLC and unambiguously identified by HRMS.

\subsection{TAR RNA binding affinity}

The TAR binding affinity was first investigated on the 16 batches $(4 \times 4)$ constituting the four sub-libraries $(\operatorname{SL}(A), \operatorname{SL}(F)$,
$\mathrm{SL}(\mathrm{K})$, and $\mathrm{SL}(\mathrm{R})$ ) (see data in Table 1 ), then on the individual triPAA 1-24 and 25-28 (see data in Table 2), by monitoring the fluorescence decrease of a $5^{\prime}$-fluorescently-labelled (Alexa 488) TAR fragment ( 27 mer, $5 \mathrm{nM}$ ) observed upon addition of increasing concentrations of either mixtures of four tri-PAA from a batch or single tri-PAA (from 0.01 to $2000 \mu \mathrm{M}$ ). These experiments were performed at $25^{\circ} \mathrm{C}$, in buffer A (20 mM HEPES (pH 7.4 at $25^{\circ} \mathrm{C}$ ), $20 \mathrm{mM} \mathrm{NaCl}, 140 \mathrm{mM} \mathrm{KCl}$, and $3 \mathrm{mM} \mathrm{MgCl}_{2}$ ), which closely approximates ionic conditions inside cells. Dissociation constants $\left(K_{\mathrm{d}}\right)$ were then determined from the binding curves, as previously described. ${ }^{10}$

\subsubsection{Library studies}

For all batches, curves fitted well a 1:1 stoichiometry model and dissociation constants $\left(K_{\mathrm{d}}\right)$ were determined, these values indicating the 'global' binding activity of the corresponding batches (Table 1). A good discrimination between the different batches was obtained with $K_{\mathrm{d}}$ values ranging from 1.5 to $150 \mu \mathrm{M}$. The sub-library containing at its $\mathrm{C}$-extremity the Ala residue (i.e., $\mathrm{SL}(\mathrm{A})$ ) globally showed the lowest binding affinity $\left(25 \mu \mathrm{M}<K_{\mathrm{d}}<150 \mu \mathrm{M}\right)$, comparatively to $\operatorname{SL}(\mathrm{K})\left(7 \mu \mathrm{M}<K_{\mathrm{d}}<65 \mu \mathrm{M}\right), \operatorname{SL}(\mathrm{R})\left(4 \mu \mathrm{M}<K_{\mathrm{d}}<\right.$ $48 \mu \mathrm{M})$, and $\operatorname{SL}(\mathrm{F})\left(1.5 \mu \mathrm{M}<K_{\mathrm{d}}<24 \mu \mathrm{M}\right)$, the later sub-library displaying the strongest affinity. In addition, within each sub-library and with respect to the nature of the PAA at the N-extremity of the trimer, the $K_{\mathrm{d}}$ value is decreasing along the Ala $\gg$ Lys $>$ $\operatorname{Arg}>$ Phe sequence. These results indicate that, unlike the Ala residue, the aromatic Phe monomer, the cationic Arg monomer and, to a lesser extent, the cationic Lys one, contribute to enhance the TAR binding affinity.

In order to identify tri-PAA hits, the 24 tri-PAA (1-24) constituting six of the most interesting batches (FXF), (RXF), (FXR), (FXK), (RXR), and (RXK) were synthesized individually (see above). Moreover, we also prepared as controls the four tri-PAA (25-28) constituting the batch (KXA), which exhibited only a poor global binding activity $\left(K_{\mathrm{d}}=107 \mu \mathrm{M}\right)$.

\subsubsection{Individual tri-PAA}

The tri-PAA 25-28 exhibited a low affinity for TAR $\left(K_{\mathrm{d}} \geqslant 46 \mu \mathrm{M}\right.$; Table 2$)$, demonstrating that global $K_{\mathrm{d}}$ values likely reflect the binding potential of the four individual tri-PAA constituting batches. Concerning compounds 1-24, $K_{\mathrm{d}}$ values ranged from 2 to $80 \mu \mathrm{M}$. Within all batches, a similar tendency was observed, the binding affinity increasing along the sequence: $\mathrm{XAX}^{\prime}<\mathrm{XKX}^{\prime} \leqslant \mathrm{XRX}^{\prime} \leqslant \mathrm{XFX}^{\prime}$. These results confirm that the Ala residue disfavors the interaction with TAR, whatever its position 
A<smiles>[Y2]C([R7])C(=O)N(CCNC=O)CC(=O)O</smiles>

Boc-PAA $\left(A A_{n}\right)(n=1-4)$

$\mathrm{R}^{1}: \mathrm{CH}_{3} ; \mathrm{PAA}(\mathrm{A})$

$\mathrm{R}^{2}: \mathrm{CH}_{2}$ - $\mathrm{Ph}$; PAA (F)

$\mathrm{R}^{3}:\left(\mathrm{CH}_{2}\right)_{4}-\mathrm{NH}-\mathrm{Z}$; PAA (K)

$\mathrm{R}^{4}:\left(\mathrm{CH}_{2}\right)_{3}-\mathrm{N}(\mathrm{Z}) \mathrm{C}(\mathrm{NH}-\mathrm{Z})=\mathrm{NH} ; \mathrm{PAA}(\mathrm{R})$
B

\begin{tabular}{|c|c|c|c|}
\hline \multicolumn{4}{|c|}{$\begin{array}{l}\text { Tri-PAA Library } \\
\text { (64 cpds) }\end{array}$} \\
\hline \multicolumn{4}{|c|}{$\begin{array}{l}4 \text { Sub-Libraries SL }\left(\mathrm{AA}_{\mathrm{n}}\right) \\
\text { (16 cpds/SL) }\end{array}$} \\
\hline SL(A) & SL(F) & SL(K) & SL(R) \\
\hline \multicolumn{4}{|c|}{$4 \times 4$ batches ( $4 \mathrm{cpds} / \mathrm{batch})$} \\
\hline$(A X A)$ & (AXF) & $(\mathrm{AXK})$ & $(A \times R)$ \\
\hline$(\mathrm{FXA})$ & $(F X F)$ & $(\mathrm{FXK})$ & $(\mathrm{FXR})$ \\
\hline$(K X A)$ & $(\mathrm{KXF})$ & $(K X K)$ & $(\mathrm{KXR})$ \\
\hline$(\mathrm{RXA})$ & (RXF) & $(\mathrm{RXK})$ & $(\mathrm{RXR})$ \\
\hline
\end{tabular}

C

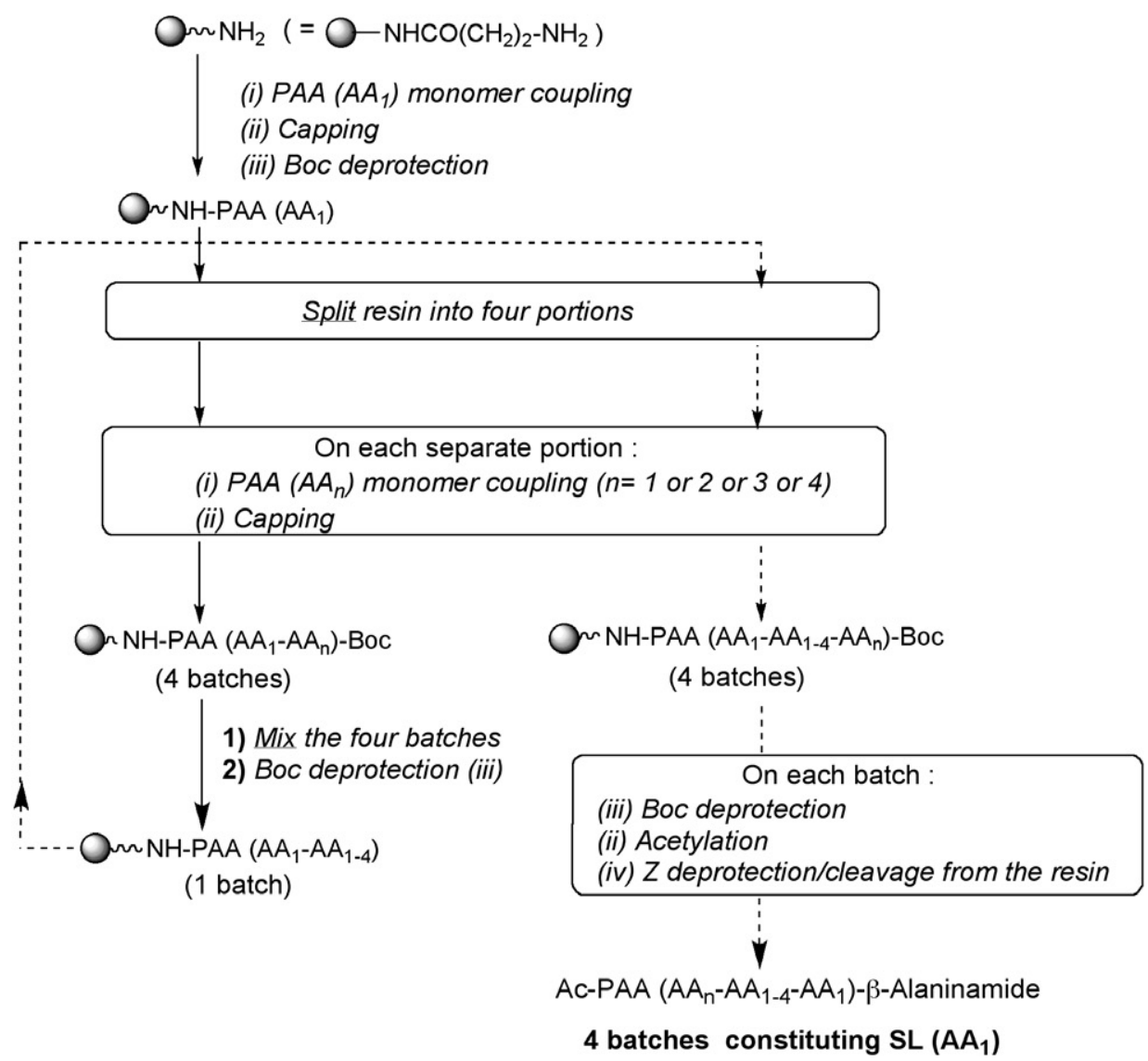

Figure 2. (A) Structure of the four Boc/Z protected PAA monomers. (B) Structure of the tri-PAA library. (C) Sub-libraries synthesis: (i) PAA (AA $)_{1}$, HBTU, DIEA, NMP; (ii) Ac ${ }_{2} \mathrm{O}$ Py/NMP (15/10/75); (iii) TFA/TIS (90/10); (iv) TFMSA/TIS/TFA (10/10/80).

Table 1

Global TAR RNA binding activities $\left(K_{\mathrm{d}}\right)$ of tri-PAA sub-libraries ${ }^{\mathrm{a}}$

\begin{tabular}{|c|c|c|c|c|c|}
\hline Sub-library SL (PAA) & Batches $\left(\mathrm{PAA}_{\mathrm{N}}-\mathrm{X}-\mathrm{PAA} \mathrm{A}_{\mathrm{C}}\right)$ & $K_{\mathrm{d}}(\mathrm{M})$ & Sub-library SL (PAA) & Batches $\left(\mathrm{PAA}_{\mathrm{N}}-\mathrm{X}-\mathrm{PAA} \mathrm{C}\right)$ & $K_{\mathrm{d}}(\mu \mathrm{M})$ \\
\hline \multirow[t]{4}{*}{ SL (A) } & (AXA) & $150 \pm 50$ & SL $(K)$ & $(\mathrm{AXK})$ & $65 \pm 8$ \\
\hline & (FXA) & $25 \pm 10$ & & $(\mathrm{FXK})$ & $7 \pm 1$ \\
\hline & (KXA) & $107 \pm 9$ & & $(\mathrm{KXK})$ & $37 \pm 4$ \\
\hline & (RXA) & $29 \pm 10$ & & (RXK) & $10 \pm 5$ \\
\hline \multirow[t]{4}{*}{$\mathrm{SL}(\mathrm{F})$} & $(\mathrm{AXF})$ & $24 \pm 6$ & SL (R) & (AXR) & $48 \pm 10$ \\
\hline & $(\mathrm{FXF})$ & $1.5 \pm 0.7$ & & (FXR) & $4.2 \pm 0.6$ \\
\hline & $(\mathrm{KXF})$ & $8 \pm 2$ & & (KXR) & $14 \pm 6$ \\
\hline & $(\mathrm{RXF})$ & $3.8 \pm 0.9$ & & (RXR) & $7 \pm 2$ \\
\hline
\end{tabular}

a All standard fluorescence measurements were performed in buffer $\mathrm{A}\left(20 \mathrm{mM} \mathrm{HEPES}\left(\mathrm{pH} 7.4\right.\right.$ at $\left.25^{\circ} \mathrm{C}\right), 20 \mathrm{mM} \mathrm{NaCl}, 140 \mathrm{mM} \mathrm{KCl}$, and $3 \mathrm{mM} \mathrm{MgCl}$ ). Each batch $\left(\mathrm{PAA} \mathrm{N}_{\mathrm{N}} \mathrm{X}\right.$ $\left.\mathrm{PAA}_{\mathrm{C}}\right)$ contains four compounds, in which the nature of the internal $\mathrm{X}$ residue varies $(\mathrm{X}=\mathrm{PAA}(\mathrm{A})$ or $(\mathrm{F})$ or $(\mathrm{K})$ or $(\mathrm{R}))$. 
Table 2

Dissociation constants $\left(K_{\mathrm{d}}\right)$ for individual tri-PAA-TAR RNA interactions ${ }^{\mathrm{a}}$

\begin{tabular}{llcllr}
\hline Batches & Tri-PAA & \multicolumn{1}{c}{$K_{\mathrm{d}}(\mu \mathrm{M})$} & Batches & Tri-PAA & $K_{\mathrm{d}}(\mu \mathrm{M})$ \\
\hline (FXF) & FAF 1 & $n^{\mathrm{n}} \mathrm{d}^{\mathrm{b}}$ & (RXF) & RAF 13 & $34 \pm 7$ \\
& FFF 2 & $\mathrm{nd}^{\mathrm{b}}$ & & RFF 14 & $3 \pm 2$ \\
& FKF 3 & $8 \pm 3$ & & RKF 15 & $7 \pm 2$ \\
& FRF 4 & $3 \pm 1$ & & RRF 16 & $2 \pm 1$ \\
$($ FXR) & FAR 5 & $22 \pm 5$ & (RXR) & RAR 17 & $80 \pm 9$ \\
& FFR 6 & $2 \pm 1$ & & RFR 18 & $8 \pm 2$ \\
& FKR 7 & $4 \pm 1$ & & RKR 19 & $12 \pm 1$ \\
& FRR 8 & $2.2 \pm 0.7$ & & RRR 20 & $14 \pm 4$ \\
(FXK) & FAK 9 & $68 \pm 8$ & (RXK) & RAK 21 & $76 \pm 20$ \\
& FFK 10 & $3 \pm 1$ & & RFK 22 & $6 \pm 1$ \\
& FKK 11 & $9 \pm 3$ & & RKK 23 & $10 \pm 3$ \\
& FRK 12 & $7 \pm 2$ & & RRK 24 & $10 \pm 4$ \\
(KXA) control & KAA 25 & $>800$ & & & \\
& KFA 26 & $46 \pm 12$ & & & \\
& KKA 27 & $109 \pm 20$ & & & \\
& KRA 28 & $76 \pm 14$ & & & \\
\hline
\end{tabular}

a All standard fluorescence measurements were performed in buffer A.

b Not determined.

within the trimer sequence, contrary to the aromatic Phe and cationic Arg residues and, to a lesser extend, Lys ones. The presence of at least one Phe residue was found to favor affinity. Indeed, 19, 20, 23, and 24 trimers, which contain only Lys/Arg residues, display a lower affinity $\left(14 \geqslant K_{\mathrm{d}} \geqslant 10 \mu \mathrm{M}\right)$ than any trimer deriving from a combination of at least one Phe with the cationic Lys/Arg residues (e.g., 3, 4, 6-8, 10-12, and 14-16). These results are in line with those observed in the case of tetra-PAA, confirming that TAR affinity does not result exclusively from non-specific electrostatic interactions with Lys and Arg units. The best tri-PAA ligands $\left(K_{\mathrm{d}}=\right.$ $2-3 \mu \mathrm{M})$ result from a combination of Phe and Arg residues, either 2 Phe/1 $\operatorname{Arg}$ (e.g., 4, 6, and 14) or 2 Arg/1 Phe (e.g., 8 and 16), excepting trimer RFR $18\left(K_{\mathrm{d}}=8 \mu \mathrm{M}\right)$. Among the Phe/Lys series, the sequence FFK $10\left(K_{d}=3 \mu \mathrm{M}\right)$ is the only one displaying an affinity for TAR comparable to that of the Phe/Arg ones.

Furthermore, in a given series, TAR affinity does not seem to depend on the trimer sequence, as tri-PAA containing the same three residues located at different positions within the trimer display comparable $K_{\mathrm{d}}$ values (see, for example, 4, 6, and 14 in the Phe/ Arg trimer series and 7, 12, 15, and 22, in the Phe/Arg/Lys series). This observation could be explained by the inherent flexibility of the PAA structure. Indeed, upon TAR binding, various conformations could be adopted, as illustrated in Figure 3, which represents models of complexes formed between TAR and three palindromic tri-PAA (FRF 4, FFR 6, and RFF 14), obtained by molecular docking experiments (data not shown). ${ }^{11}$ Following these models, these three compounds bind, as in the case of Tat protein and Tat derived analogues, to the major groove of TAR, $\mathbf{4}$ and $\mathbf{6}$ in a folded conformation and $\mathbf{1 4}$ in an extended one.

TAR RNA specificity of the eight tri-PAA displaying the highest affinities was evaluated in the presence of tRNA and dsDNA as competitors. Binding affinities $K_{\mathrm{d}}^{\prime}$ and $K_{\mathrm{d}}^{\prime \prime}$ (collected in Table 3 ) were measured in the presence of a 100-fold nucleotide excess of either a mixture of natural tRNA or a 15-mer DNA duplex, respectively. For all the tri-PAA tested, only a slight TAR affinity decrease was observed in presence of tRNA (maximum threefold for FKR 7 and RFF 14), demonstrating a high TAR RNA versus tRNA specificity, as observed for longer PAA. ${ }^{10}$ On the other hand, and unlike tetra-PAA, which were shown to have a high TAR RNA versus DNA specificity even in the case of highly charged derivatives, tri-PAA exhibit a 5-14-fold lower TAR affinity in the presence of DNA competitor. This decrease of specificity is not correlated to the number of cationic charges on tri-PAA (see, for example, $K_{\mathrm{d}}^{\prime \prime} / K_{\mathrm{d}}$ values for tetra-cationic FFK 10 (11.9) and penta-cationic RKF 15 (4.4)) but seems to be rather sequence-dependent, as demonstrated by comparing, for example, the specificity ratio $K_{\mathrm{d}}^{\prime \prime} / K_{\mathrm{d}}$ for tetra-cationic 'anagram' compounds FRR 8 and RRF $16\left(K_{\mathrm{d}}^{\prime \prime} / K_{\mathrm{d}}=5.7\right.$ and 13.6, respectively).

\subsection{FRET study of Tat/TAR complex inhibition}

The extent to which tri-PAA could disrupt the TAR/tat complex was investigated with trimers $4,6,8$, and 14-16, which are among the best ligands. This study was performed using a FRET-based competition assay based on the Alexa (A488) 5'-labelled-TAR RNA fragment as the fluorescent donor and a Tat (47-58) fragment labeled with rhodamine as the fluorescent acceptor (Rh-Tat). ${ }^{12}$ Association of Rh-Tat with the A488-TAR RNA resulted in a 1.4-fold decrease in fluorescence, probably by driving the peptide in an extended conformation, which allows the energy transfer between the two dyes to occur. Titrating A488-TAR with Rh-Tat established the $1: 1$ complex stoichiometry. In our conditions, a $K_{\mathrm{d}}$ value of $25 \mathrm{nM}$ could be calculated from these data, which is in the same range than reported values. ${ }^{12,13}$ We performed single-point measurements of the inhibition potency of the candidate molecules at four fixed concentrations $(1,10,100$, and $400 \mu \mathrm{M})$. In all cases, an increase of the fluorescence emission was observed, demonstrating that tri-PAA compete with the Tat fragment for the same binding site on TAR. All tested compounds were able to completely displace Tat at the highest concentration, the most potent compounds, RFF 14, RKF 15, and RRF 16 displaying an $\mathrm{IC}_{50}$ value around $1 \mu \mathrm{M}$ (Fig. 4).

\subsection{Antiviral potency of tri-PAA compounds}

To have an insight into the potential of PAA to inhibit the HIV-1 replication, the antiviral activity of the six tri-PAA 4, 6, 8, and 1416, was evaluated on phytohemaglutinin-P (PHA-P)-activated PBMC experimentally infected with the X4-tropic HIV-1-LAI strain, which possesses the same TAR sequence than the mini-TAR used in this study for acellular assays. Before the infection step, cells were pre-treated for $30 \mathrm{~min}$ with the PAA, at a concentration of $100 \mu \mathrm{M}$. At the same time, cytotoxicity of the sample was evaluated in uninfected PHA-P-activated PBMC, by the classical MTT assay. As shown in Table 4, all tested PAA decreased at $100 \mu \mathrm{M}$ the HIV replication (around 50-60\%) and the cell viability (around 30\%). No clear difference could be seen between these six compounds. Further experiments are required to elucidate the origine of this antiviral activity and toxicity. Concerning the later, it may be related to the low TAR versus DNA specificity observed in the case of these tri-PAA.

\section{Conclusions}

Starting from a small library of 64 tri-PAA generated from only 4 different amino acids, we have identified several compounds able to bind TAR RNA as tightly as tetra-PAA, that is, with a micromolar affinity, but with a lower TAR RNA versus DNA specificity. These compounds also prevent the Tat/TAR association at a micromolar level. Even if they display only a moderate antiviral activity and some cytotoxicity, altogether these results are encouraging as this library of short length PAA explores only a very small part of the combinatorial diversity potentially achievable for this family of compounds. Thus, one can expect that introducing other amino acid residues than the four taken as models in this study could lead to TAR tri-PAA ligands with both an improved affinity and specificity for the target. Moreover, constraining the conformational freedom of these highly flexible trimeric structures by cyclization could also impact on these two parameters. Overall, PAA represent interesting structures for the development of more potent HIV TAR/tat inhibitors. 

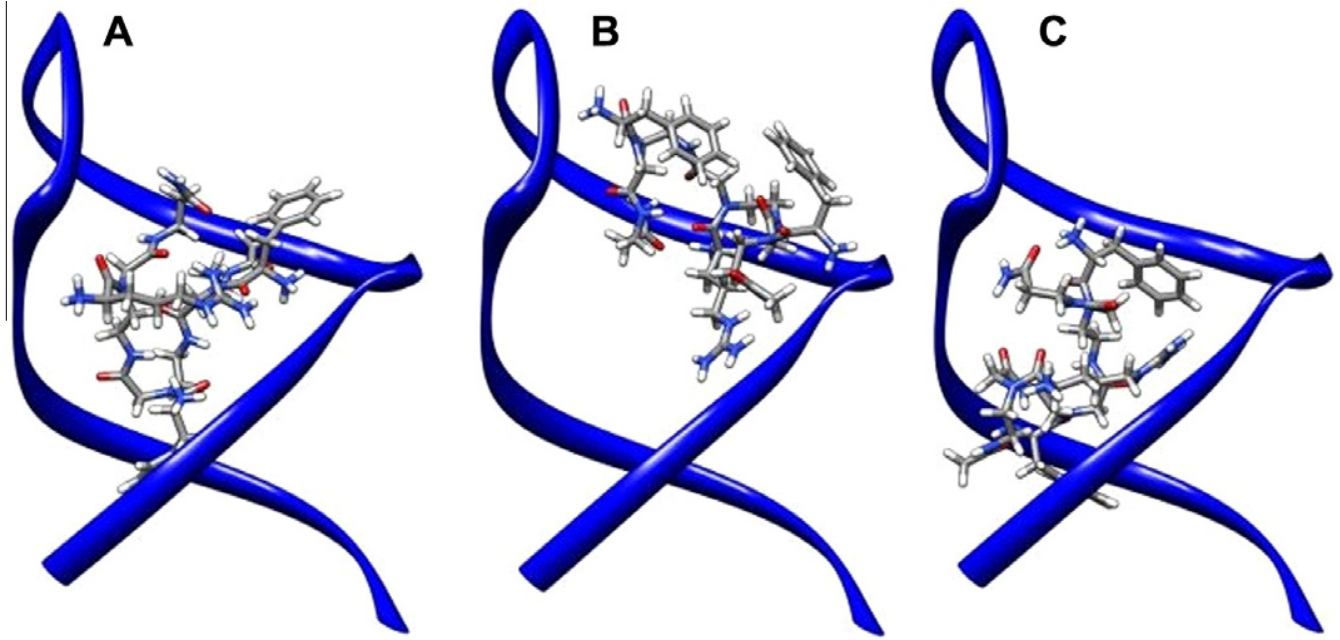

Figure 3. Models illustrating the binding of three palindromic tri-PAA with HIV-1 TAR RNA. (A) FRF (4); (B) FFR (6); (C) RFF (14). ${ }^{11}$

Table 3

Dissociation constants for tri-PAA-TAR RNA interactions in the absence $\left(K_{\mathrm{d}}\right)$ and in the presence of tRNA $\left(K_{\mathrm{d}}^{\prime}\right)$ and DNA $\left(K_{\mathrm{d}}^{\prime \prime}\right)$ competitors ${ }^{\mathrm{a}}$

\begin{tabular}{|c|c|c|c|c|c|}
\hline Tri-PAA & $K_{\mathrm{d}}(\mathrm{TAR})(\mu \mathrm{M})$ without competitor & $K_{\mathrm{d}}^{\prime}(\mathrm{TAR})(\mu \mathrm{M})$ with tRNA mix ${ }^{\mathrm{b}}$ & $K_{\mathrm{d}}^{\prime} / K_{\mathrm{d}}$ & $K_{\mathrm{d}}^{\prime \prime}(\mathrm{TAR})(\mu \mathrm{M})$ with dsDNA ${ }^{\mathrm{c}}$ & $K_{\mathrm{d}}^{\prime \prime} / K_{\mathrm{d}}$ \\
\hline FRF 4 & $3 \pm 1$ & $1.1 \pm 0.4$ & 0.4 & $17.5 \pm 4.3$ & 5.8 \\
\hline FFR 6 & $2 \pm 1$ & $4.3 \pm 1.8$ & 2.1 & $28.4 \pm 4.5$ & 14.2 \\
\hline FKR 7 & $4 \pm 1$ & $12 \pm 8$ & 3 & $33.6 \pm 6.2$ & 8.4 \\
\hline FRR 8 & $2.2 \pm 0.7$ & $2.2 \pm 1.1$ & 1 & $12.5 \pm 2.8$ & 5.7 \\
\hline FFK 10 & $2.8 \pm 1.0$ & $5.9 \pm 1.4$ & 2.1 & $33.3 \pm 4.2$ & 11.9 \\
\hline RFF 14 & $3 \pm 2$ & $9.1 \pm 3.7$ & 3 & $14.9 \pm 4.2$ & 4.9 \\
\hline RKF 15 & $7 \pm 2$ & $4.4 \pm 0.8$ & 0.6 & $31.1 \pm 6.5$ & 4.4 \\
\hline RRF 16 & $2 \pm 1$ & $2.7 \pm 0.6$ & 1.3 & $27.3 \pm 5.9$ & 13.6 \\
\hline
\end{tabular}

a All standard fluorescence measurements were performed in buffer A (20 mM HEPES (pH 7.4 at $\left.25^{\circ} \mathrm{C}\right), 20 \mathrm{mM} \mathrm{NaCl}, 140 \mathrm{mM} \mathrm{KCl}$, and $3 \mathrm{mM} \mathrm{MgCl}$ ).

b Measured in the presence of a 100-fold nucleotide excess of a mixture of natural tRNA (tRNAmix).

c Measured in the presence of a 100-fold nucleotide excess of a 15-mer duplex DNA.

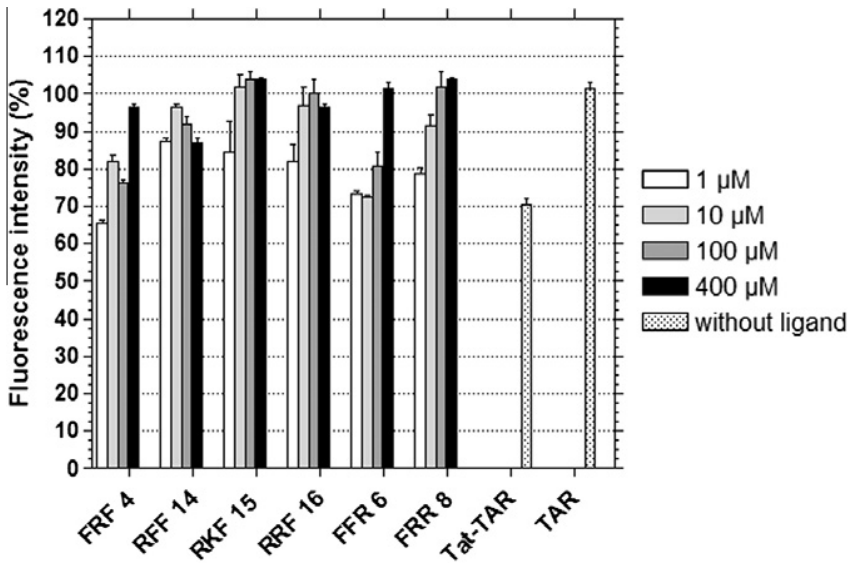

Figure 4. TAR/tat complex inhibitor effect of tri PAA.

\section{Experimental section}

\subsection{Material and methods}

Solvents and reagents were obtained from commercial sources and used without further purification. N-protected PAA monomers were synthesized as described previously. ${ }^{10}$ HPLC analyses were performed at room temperature on a Thermo RP18 column (3.2 $\times 250 \mathrm{~mm}, 5 \mu \mathrm{m}, 300 \AA)$ using a Waters apparatus (St Quentin en Yvelines, France) including HPLC Alliance 2695, 996 photodiode
Table 4

Anti-HIV activity and cellular toxicity of selected tri-PAA

\begin{tabular}{lll}
\hline Tri-PAA & \% of HIV-1 inhibition at $100 \mu \mathrm{M}$ & \% cellular toxicity at $100 \mu \mathrm{M}$ \\
\hline FRF 4 & $53 \pm 5$ & $26 \pm 1$ \\
FFR 6 & $60 \pm 17$ & $27 \pm 1$ \\
FKR 7 & $46 \pm 6$ & $29 \pm 2$ \\
FRR 8 & $56 \pm 4$ & $28 \pm 5$ \\
FFK 10 & $51 \pm 5$ & $26 \pm 4$ \\
RFF 14 & $53 \pm 11$ & $33 \pm 6$ \\
RKF 15 & $54 \pm 6$ & $33 \pm 6$ \\
RRF 16 & $58 \pm 13$ & $29 \pm 5$
\end{tabular}

array detector. $0.1 \%$ TFA/water (Solvent $\mathrm{A}$ ) and $0.1 \%$ TFA/acetonitrile (Solvent $B$ ) were used as elution solvents. A gradient of $A / B$ ( $100 / 0$ for $7 \mathrm{~min}$ then $100 / 0$ to $50 / 50$ for $23 \mathrm{~min}$ ) was employed at a flow rate of $1 \mathrm{~mL} / \mathrm{min}$. Semi-preparative HPLC were performed on a Waters system (600E system controller, 2487 dual wavelength absorbance detector) with a Thermo RP18 column $(10 \times 250 \mathrm{~mm}, 5 \mu \mathrm{m}, 300 \AA)$ at a flow rate of $3 \mathrm{~mL} / \mathrm{min}$, with the same solvent gradient as for analytical separations. Lyophilization was performed on a Flexy-Dry FTS system. ESI HRMS analysis was carried out on an LTQ Orbitrap hybrid mass spectrometer with an electrospray ionization probe (Thermo Scientific, San Jose, CA) by direct infusion from a pump syringue, to confirm correct molar mass and high purity of the compounds. ${ }^{1} \mathrm{H}$ and COSY spectra were recorded with a Brucker AV 500 spectrometer, using deuterated $\mathrm{D}_{2} \mathrm{O}$ purchased from euristop. For all tri-PAA, the presence of a mixture of several isomers cause signals multiplication, giving 
complex ${ }^{1} \mathrm{H}$ spectra. Thus, the reported data are those of the major conformers.

\subsection{Synthesis}

The tri-PAA library as well as individual tri-PAA were prepared on MBHA resin LL (100-200 mesh, $0.67 \mathrm{mmol} / \mathrm{g}$, Novabiochem) starting from the four protected PAA monomers Boc-PAA ( $\mathrm{Ala}^{\mathrm{Z}}$ ), Boc-PAA $\left(\mathrm{Phe}^{\mathrm{Z}}\right)$, Boc-PAA $\left(\mathrm{Lys}^{\mathrm{Z}}\right)$, and Boc-PAA $\left(\operatorname{Arg}^{\mathrm{Z}}\right)$, whose synthesis has been previously published. ${ }^{10}$ Syntheses were performed in a $20 \mathrm{~mL}$ glass peptide vessel fitted with a polyethylene filter disk. Solvents and soluble reagents were removed by filtration under Argon. All syntheses and washes were done at $25^{\circ} \mathrm{C}$.

\subsubsection{Tri-PAA library}

The tri-PAA library was elaborated following a split-and-mix strategy. Sub-libraries SL (F), (K), and (R) were prepared as described below for the synthesis of the sub-library SL (A), given as an example:(a) A preactivated ( $3 \mathrm{~min}$ ) mixture of Boc- $\beta$-alanine (28.3 $\mathrm{mg}, 0.15 \mathrm{mmol})$, DIEA $(105 \mu \mathrm{L}, 0.6 \mathrm{mmol})$, and HBTU $(57 \mathrm{mg}, 0.15 \mathrm{mmol})$ in $1.5 \mathrm{~mL}$ of NMP was added to $450 \mathrm{mg}$ $(0.3 \mathrm{mmol})$ of MBHA resin. After $2 \mathrm{~h}$ of stirring, the resin was washed with NMP until pH 7. (b) The remaining amino groups on the resin were capped using a $\mathrm{Ac}_{2} \mathrm{O} / \mathrm{Pyr} / \mathrm{NMP}$ (15:15:70, $\mathrm{v}$ :v:v) solution $(2 \times 4 \mathrm{~mL} ; 2 \times 10 \mathrm{~min})$, then the resin was washed with NMP $(2 \times 10 \mathrm{~mL})$ and DCM $(3 \times 10 \mathrm{~mL})$. (c) The Boc group was cleaved with a TFA/TIS $(9: 1, v: v)$ solution $(2 \times 4 \mathrm{~mL}$; $2 \times 15 \mathrm{mn})$ then the resin was washed with $\mathrm{DCM}(3 \times 10 \mathrm{~mL})$ and NMP $(2 \times 4 \mathrm{~mL})$. (d) A preactivated ( $3 \mathrm{~min})$ mixture of BocPAA ( Ala $\left.^{\mathrm{Z}}\right)$ monomer $(0.225 \mathrm{mmol})$, DIEA $(183 \mu \mathrm{L}, 1.05 \mathrm{mmol})$, and HBTU ( $80 \mathrm{mg}, 0.21 \mathrm{mmol}$ ) in $2 \mathrm{~mL}$ of NMP was added to the resin. After $1 \mathrm{~h}$ of stirring, the resin was washed with NMP $(2 \times 10 \mathrm{~mL})$ and DCM $(3 \times 10 \mathrm{~mL})$. This coupling step was monitored by a Kaiser test and repeated twice. After capping of unreacted amino groups (step b), the resin was dried then split into four portions. On each portion, after cleavage of the Boc group and resin washing (step c), one preactivated Boc-PAA protected monomer among the four was condensed, using the same procedure than above (step d). After a capping step (step b), the four portions were mixed then subjected to a common Boc deprotection (step c) before being dried then split into four batches. To each batch was condensed one Boc-PAA protected monomer among the four (step d). After Boc cleavage (step c) and N-acetylation of the last PAA residue (step b), each batch was submitted to acidolysis using a 1:8:1 (v:v:v) TFMSA/TFA/TIS solution ( $4 \mathrm{~mL}, 4 \mathrm{~h})$. For each batch, the resulting solution combined with $1 \mathrm{~mL}$ of TFA (used to wash the resin) was then added to cold diethyl ether $(30 \mathrm{~mL})$ and the solution was centrifugated $(10 \mathrm{mn}, 3000 \mathrm{tr} / \mathrm{mn})$. The supernatant was removed, the residual solid was washed with $30 \mathrm{~mL}$ of diethyl ether and the resulting solution was centrifugated. This step was repeated three times. The solid was then dissolved in water and the mixture, containing four tri-PAA, was basically purified by HPLC semi-preparative (100\% A for 7 min then $100 \% \mathrm{~A}$ to $50 \% \mathrm{~A} / 50 \% \mathrm{~B}$ for $23 \mathrm{~min}$; flow rate: $3 \mathrm{~mL} / \mathrm{min})$. After lyophilization, the content of the four batches constituting the SL (A) sub-library was analysed by ESI MS experiments.

\subsubsection{Individual tri-PAA}

Individual tri-PAA were elongated on $\beta$-alanine functionalized MBHA resin (300 mg), following the standard procedure: (i) coupling conditions: couplings were performed with a NMP solution ( $1.5 \mathrm{~mL}$ ) containing a preactivated (3 $\mathrm{min})$ mixture of Boc-PAA protected monomer ( 1.5 equiv), DIEA ( 7 equiv), and HBTU (1.4 equiv). Each coupling step was monitored by a Kaiser test and repeated twice. (ii) Boc cleavage: TFA/TIS (9:1, v:v), $2 \times 15$ min, DCM wash, NMP wash. (iii) Cleavage from the resin: the compounds were cleaved (and totally deprotected) using a TFMSA/TFA/TIS (1:8:1, v:v:v) solution ( $3 \mathrm{~mL}$ ) for $4 \mathrm{~h}$. The resulting solution combined with $1 \mathrm{~mL}$ of TFA (used to wash the resin) was added to cold anhydrous diethyl ether $(20 \mathrm{~mL})$ and the mixture was centrifugated $(10 \mathrm{mn}$, $3000 \mathrm{tr} / \mathrm{mn}$ ). The supernatant was removed, the crude solid triPAA was washed with $30 \mathrm{~mL}$ of diethyl ether and the resulting solution was centrifugated. This step was repeated three times. Tri-PAA were then dissolved in water and purified by semi-preparative HPLC (A/B: $100 / 0$ for 7 min then $100 / 0$ to $50 / 50$ for $23 \mathrm{~min}$, flow rate of $1 \mathrm{~mL} / \mathrm{min}$ ). After lyophilization, their structure were confirmed by HRMS experiments.

\subsection{Fluorescence binding assays}

Unless otherwise stated, all reagents and solvents were of biomolecular grade and from Sigma (St Louis, USA). HEPES [4-(2hydroxyethyl)-1-piperazineethanesulfonic acid] and all inorganic salts for buffers were purchased from Calbiochem (molecular biology grade). TAR RNA and DNA oligonucleotides were purchased from IBA GmbH and used without further purification. A mixture of pre- and mature yeast tRNAs (containing over 30 different species from baker's yeast Saccharomyces cerevisiae) was purchased from Sigma (type X-SA). Stocks of tRNAmix can be quantified in its native form (without base hydrolysis) using an extinction coefficient of $9640 \mathrm{~cm}^{-1} \mathrm{M}^{-1}$ per base. ${ }^{14}$

All standard fluorescence measurements were performed in buffer A ( $20 \mathrm{mM}$ HEPES ( $\mathrm{pH} 7.4$ at $25^{\circ} \mathrm{C}$ ), $20 \mathrm{mM} \mathrm{NaCl}, 140 \mathrm{mM} \mathrm{KCl}$, and $3 \mathrm{mM} \mathrm{MgCl} 2$ ). Buffers were filtered through $0.22-\mu \mathrm{m}$ Millipore filters (GP ExpressPLUS membrane). A small aliquot (50-100 mL) was first filtered and then discarded to avoid any contaminants that might be leached from the filter. The solutions to be used in the fluorescence experiments were prepared by diluting the concentrated stocks in Milli-Q water and filtered again as described above.

For competitive experiments in the presence of a $d s$ DNA, a 15mer sequence ( $5^{\prime}$-CGTTTTTATTTTTGC- $3^{\prime}$ ) and its complement, annealed beforehand, were added to buffer $A$ to obtain a 100 -fold nucleotide excess regarding TAR RNA ( 900 nM duplex; 5 nM RNA).

For competitive experiments in the presence of a $t$ RNA, the mixture of pre- and mature yeast $t$ RNAs was added to buffer A to obtain a 100-fold nucleotide excess regarding TAR RNA. Stock solutions of $t$ RNA were prepared in water and quantified using an extinction coefficient of $9640 \mathrm{~cm}^{-1} \mathrm{M}^{-1}$ per base. ${ }^{14}$

Ligand solutions were prepared as serial dilutions by an epMotion automated pipetting system (eppendorf) in buffer A at a concentration two times higher than the desired final concentration to allow for the subsequent dilution during the addition of the RNA solution. The appropriate ligand solution $(50 \mu \mathrm{L})$ was then added to a well of a non-treated black 96-well plate (Nunc 237105), in triplicate. Refolding of the RNA was performed using a thermocycler (ThermoStat Plus Eppendorf) as follows: the RNA, diluted in $1 \mathrm{~mL}$ of buffer $\mathrm{A}$, was first denatured by heating to $90^{\circ} \mathrm{C}$ for $2 \mathrm{~min}$ then cooled to $4{ }^{\circ} \mathrm{C}$ for $10 \mathrm{~min}$ followed by incubation at $20^{\circ} \mathrm{C}$ for $15 \mathrm{~min}$. After refolding, the RNA was diluted to a working concentration of $10 \mathrm{nM}$ through addition of the appropriate amount of buffer $\mathrm{A}$. The tube was mixed and $50 \mu \mathrm{L}$ of the RNA solution was added to each well containing ligand. This subsequent dilution lowered the final RNA concentration to $5 \mathrm{nM}$. The fluorescence was measured on a GeniosPro (Tecan) with an excitation filter of $485 \pm 10 \mathrm{~nm}$ and an emission filter of $535 \pm 15 \mathrm{~nm}$. Each point was measured 10 times with a $500 \mu$ s integration time and averaged. Binding was allowed to proceed overnight at $5{ }^{\circ} \mathrm{C}$ to achieve equilibrium.

\subsection{Tat/TAR complex inhibition study by FRET assay}

Determination of FRET assay fluorescence-based binding assays were performed in 96 -well microplates (nunc) at $25^{\circ} \mathrm{C}$ and the 
fluorescence was measured on a GeniosPro (Tecan) with an excitation filter of $485 \pm 10 \mathrm{~nm}$ and an emission filter of $535 \pm 15 \mathrm{~nm}$. TAR and Tat49-57 peptide (sequence: Rhodamine-YGRKKRRQRRRP, EzBiolab, USA) were both used at concentrations of $10 \mathrm{nM}$ in buffer B (50 mM Tris- $\mathrm{HCl}, 20 \mathrm{mM} \mathrm{KCl}, 0.02 \%$ Tween 20, pH 7.4). Prior to analyses, the RNA was treated as described above.

The emission of the background (TK buffer only), pure peptide and of the Tat-TAR complex was established first. Single-point measurements of potential inhibitors were then carried out in triplicates at varying concentrations.

\subsubsection{Data analysis}

Binding data were analyzed using the non-linear least-squares numerical solver-based binding data global analysis program BIOEQS, in which the calculated binding surface is obtained using a numerical constrained optimization chemical equilibrium solver. ${ }^{15}$ Unless otherwise stated, binding profiles were well modeled using a simple model assuming the one to one stoichiometry. $\Delta G^{\circ}$ values were converted to $K_{\mathrm{d}}$ values as $K_{\mathrm{d}}=e^{-\left(\Delta G^{\circ} / R T\right)}$.

\subsection{Antiviral activity of tri-PAA compounds}

Antiviral activity of the six selectioned tri-PAA was evaluated on phytohemaglutinin-P (PHA-P)-activated PBMC experimentally infected with the X4-tropic HIV-1-LAI strain. ${ }^{16}$ These cells pre-treated for $30 \mathrm{~min}$ by six concentrations of each drug (1:10 dilutions between $100 \mu \mathrm{M}$ and $1 \mathrm{nM}$ ) and infected with one hundred $50 \%$ tissue culture infectious doses (TCID50) of the HIV-1-LAI strain. This virus was amplified in vitro on PHA-P-activated PBMC and the viral stock titrated using PHA-P-activated PBMC and the Kärber's formula. In our antiviral assay, molecules were maintained throughout the culture, and cell supernatants were collected at day 7 post-infection and stored at $-20^{\circ} \mathrm{C}$. Azidothymidine (AZT) at $10 \mathrm{nM}$ was used in these experiments as internal control; this AZT concentration corresponds to the ED99 in our experimental model. ${ }^{17}$ Viral replication was measured by quantifying reverse transcriptase (RT) activity in cell culture supernatants using the RetroSys HIV RT kit (Innovagen). In parallel, cytotoxicity of the samples was evaluated in uninfected PHA-P-activated PBMC by methyltetrazolium salt (MTT) assay on day 7. Experiments were performed in triplicate and percents of inhibition were calculated to quantify the cell viability and the anti-HIV activity of each PAA compound.

\section{Acknowledgements}

We thank SIDACTION, the Agence Nationale de Recherche sur le SIDA and the Caisse Primaire d'Assurance Maladie des Professions Libérales for financial support. V. Bonnard and L. Pascale are recipients of a MENRT Ph.D. fellowship. We gratefully acknowledge Dr. Christophe Guilbert (Department of Pharmaceutical Chemistry, University of California San Francisco) for molecular docking experiments.

\section{Supplementary data}

Supplementary data associated with this article can be found, in the online version, at doi:10.1016/j.bmc.2010.09.002.

\section{References and notes}

1. Thomas, J. R.; Hergenrother, P. J. Chem. Rev. 2008, 108, 1171.

2. Chow, C. S.; Bogdan, F. M. Chem. Rev. 1997, 97, 1489.

3. Karn, J. J. Mol. Biol. 1999, 293, 235.

4. Aboul-ela, F.; Karn, J.; Varani, G. Nucleic Acids Res. 1996, 24, 3974.

5. Frankel, A. D. Curr. Opin. Genet. Dev. 1992, 2, 293.

6. Wei, P.; Garber, M. E.; Fang, S. M.; Fischer, W. H.; Jones, K. A. Cell 1998, 92, 451.

7. Garber, M. E.; Wei, P.; Kewal Ramani, V. N.; Mayall, T. P.; Herrmann, C. H.; Rice, A. P.; Littman, D. R.; Jones, K. A. Genes Dev. 1998, 12, 3512.

8. Richter, S. N.; Cao, H.; Rana, T. M. Biochemistry 2002, 41, 6391.

9. Dinesh, C. U.; Rana, T. M.. In Small Molecule DNA and RNA Binders; Demeunynck, M., Bailly, C., Wilson, W. D., Eds.; Wiley-VCH: Weinheim, 2003; Vol. 1, pp 5887. Chapter 4; Luedtke, N. W.; Tor, Y.. In Small Molecule DNA and RNA Binders; Demeunynck, M., Bailly, C., Wilson, W. D., Eds.; Wiley-VCH: Weinheim, 2003; Vol. 1, pp 18-40. Chapter 2; Richter, S. N.; Palù, G. Curr. Med. Chem. 2006, 13, 1305; Yang, M. Curr. Drug Targets Infect. Disord. 2005, 5, 433; Krebs, A.; Ludwig, V.; Boden, O.; Gobel, M. W. ChemBioChem 2003, 4, 972; Froeyen, M.; Herdewijn, P. Curr. Top. Med. Chem. 2002, 2, 1123.

10. Bonnard, V.; Azoulay, S.; Di Giorgio, A.; Patino, N. Chem. Commun. 2009, 2302.

11. Docking experiments were carried out using the virtual docking program MORDOR (Molecular Recognition with a Driven Dynamics optimizer). For details on MORDOR, see: Guilbert, C.; James, T. L. J. Chem. Inf. Model. 2008, 48, 1257. Pinto, I. G.; Guilbert, C.; Ulyanov, N. B.; Stearns, J.; James, T. L. J. Med. Chem. 2008, 51, 7205.

12. Cao, H.; Tamilarasu, N.; Rana, T. M. Bioconjug. Chem. 2006, 17, 352.

13. Murchie, A. I. H.; Davis, B.; Isel, C.; Afshar, M.; Drysdale, M. J.; Bower, J.; Potter, A. J.; Starkey, I. D.; Swarbrick, T. M.; Mirza, S.; Prescott, C. D.; Vaglio, P.; Aboulela, F.; Karn, J. J. Mol. Biol. 2004, 336, 625.

14. Luedtke, N. W.; Liu, Q.; Tor, Y. Biochemistry 2003, 42, 11391.

15. Royer, C. A. Anal. Biochem. 1993, 210, 91.

16. Barré-Sinoussi, F.; Chermann, J. C.; Rey, F.; Nugeyre, M. T.; Chamaret, S.; Gruest, J.; Dauguet, C.; Axler-Blin, C.; Vezinet-Brun, F.; Rouzioux, C.; Rozenbaum, W.; Montagnier, L. Science 1983, 220, 868.

17. Baleux, F.; Loureiro-Morais, L.; Hersant, Y.; Clayette, P.; Arenzana-Seisdedos, F.; Bonnaffé, D.; Lortat-Jacob, H. Nat. Chem. Biol. 2009, 5, 743. 